\title{
Pelatihan Post-Produksi (Audio-Visual Editing) Film Indie di Armidale English College Soreang, Bandung
}

\author{
Rangga Saptya Mohamad Permana ${ }^{1}$, Lilis Puspitasari ${ }^{2}$, Sri Seti Indriani ${ }^{3}$ \\ 1, 2, 3 Universitas Padjadjaran
}

\begin{tabular}{|c|c|}
\hline Article History & ABSTRACT \\
\hline $\begin{array}{l}\text { Received 20.11.2018 } \\
\text { Received in revised form } \\
16.01 .2019 \\
\text { Accepted } 01.04 .2019 \\
\text { Available online } 09.04 .2019\end{array}$ & $\begin{array}{l}\text { INDIE FILM EDITING TRAINING AT ARMIDALE ENGLISH COLLEGE OF } \\
\text { SOREANG, BANDUNG REGENCY. A film can be seen as a medium of mass } \\
\text { communication because in a film there are elements of entertainment, education, } \\
\text { and information. In fact, a film can be an advocacy media that encourages a social } \\
\text { change. In the film production management, there are major label and indie label } \\
\text { concepts, where the indie label focuses on film content and filmmakers' freedom of } \\
\text { expression. The stages that must be passed by a filmmaker in producing a film } \\
\text { starts from the stages of development, pre-production, production, post- } \\
\text { production, and distribution. The post-production stage is the most important } \\
\text { stage that determines whether a film is classified as a quality film or not because it } \\
\text { involves the final touch of a film. Therefore, the author decided to make a } \\
\text { community service program in the form of post-production indie film training } \\
\text { (audio-visual editing) at Armidale English College, Soreang District, Bandung } \\
\text { Regency. The purpose of this training is to provide practical understanding and } \\
\text { skills in the field of audio-visual editing to the trainees. The various } \\
\text { implementation methods used in this training included media communication } \\
\text { methods (audio-visual), lecture methods, interactive methods, pre-test and post- } \\
\text { test methods, and simulation methods. The results achieved after the training was } \\
\text { carried out were that the trainees experienced increased understanding and skills } \\
\text { in the context of indie film post-production, especially in the process of audio- } \\
\text { visual films editing.Keywords: Audio-Visual, Editing, Indie Film, Post-Production, } \\
\text { Training. }\end{array}$ \\
\hline & Keywords: Audio-Visual, Editing, Indie Film, Post-Production, Training. \\
\hline
\end{tabular}

DOI: $10.30653 / 002.201941 .88$

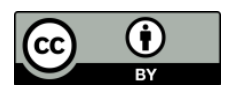

This is an open access article distributed under the terms of the Creative Commons Attribution 4.0 International License, which permits unrestricted use, distribution, and reproduction in any medium, provided the original work is properly cited. ๔ 2019 Rangga Saptya Mohamad Permana, Lilis Puspitasari, Sri Seti Indriani.

\section{PENDAHULUAN}

Film bisa dipandang sebagai hasil karya cipta manusia yang mengandung unsur estetika yang tinggi, atau bisa juga dipandang sebagai media komunikasi, di mana film bisa dipakai sebagai media untuk menyalurkan dan menyebarkan pesan-pesan dari pembuat film kepada khalayak. Jika kita memandang film dari perspektif kedua, bisa dikatakan kalau kita memandang film dari perspektif komunikasi, karena film termasuk

${ }^{1}$ Corresponding author: Program Studi Televisi dan Film, Fakultas Ilmu Komunikasi, Universitas Padjadjaran Jl. Raya Bandung-Sumedang KM. 21 Sumedang 45363; Tel.: +62 (22) 84288888. Email: rangga.saptya@unpad.ac.id 
ke dalam salah satu bentuk media massa. Jadi, jika seorang produser memproduksi sebuah film untuk menyampaikan pesan-pesan tertentu melalui film yang diproduksinya, berarti dia telah melakukan komunikasi massa. Definisi komunikasi massa yang paling sederhana dikemukakan oleh Bittner (Ardianto, Komala, \& Karlinah, 2007) yaitu komunikasi massa adalah pesan yang dikomunikasikan melalui media massa pada sejumlah besar orang. Beberapa karakteristik komunikasi massa diantaranya pesan bersifat umum, komunikannya anonim, heterogen dan tersebar, serta bersifat satu arah.

Walter Benjamin mengatakan bahwa film adalah "articulates all the problems of modern-form giving". Benjamin mencoba mengungkapkan bahwa film tidak sekedar representasi dari kenyataan, namun film adalah proses penciptaan kenyataan sendiri. Dengan kata lain, sebuah film dapat menjadi sebuah karya seni dan media penyampai pesan yang di dalamnya mengandung peristiwa-peristiwa atau fenomena-fenomena, baik itu sebuah realitas yang benar-benar terjadi di dunia nyata maupun sebuah imaji rekaan yang terjadi dalam alam alternatif ciptaan sang pembuat film (Siregar, 2011).

Film bukan hanya dipandang sebagai media massa semata, tetapi juga dipandang sebagai institusi bisnis. Menurut Dominick, industri film adalah industri bisnis. Predikat ini telah menggeser anggapan orang yang masih meyakini bahwa film adalah karya seni, yang diproduksi secara kreatif dan memenuhi imajinasi orang-orang yang bertujuan memperoleh estetika (keindahan) yang sempurna. Meskipun pada kenyataannya adalah bentuk karya seni, industri film adalah bisnis yang memberikan keuntungan, kadangkadang menjadi mesin uang yang seringkali, demi uang, keluar dari kaidah artistik film itu sendiri (Ardianto et al, 2007).

Dalam tataran manajemen produksi film, terdapat konsep major label dan indie label. Major label cenderung menitikberatkan pada aspek industri yang mempertimbangkan untung-rugi, sementara indie label lebih mementingkan faktor idealisme yang menjadi ciri utama. Kedua konsep ini selalu menjadi dua perspektif yang kontras, di mana major label akan memproduksi film-film mainstream yang mayoritas bertujuan menghasilkan keuntungan semata, sementara indie label memproduksi film-film yang lebih idealis. Jika film-film mainstream merupakan film dimana jenis pendanaannya membutuhkan jumlah besar dan keuntungan serta kerugiannya sangat diperhitungkan, maka film indie diasumsikan sebagai film yang dibuat tidak semata-mata mengandalkan pendanaan yang besar, tetapi lebih mengutamakan materi/isi dari filmnya sendiri (Putri, 2013).

Pada zaman sekarang, di mana teknologi telah berkembang pesat dan alat-alat audio-visual semakin mudah dan murah didapatkan, siapa saja dapat membuat film indie, di mana dalam film-film hasil karyanya, para sineas dapat mengekspresikan pikiran dan perasaan mereka tanpa adanya campur tangan dan kepentingan dari pihak lain. "Kekerdilan" film indie justru menjadi keuntungan bagi banyak pembuat film, mereka mampu untuk mengambil risiko dan membuat film di luar mainstream. Segmen film indie yang biasanya diperuntukkan bagi khalayak yang lebih kecil mampu menjadi lebih "gelap", lebih subversif, dan bahkan secara politis tidak benar, karena mereka tidak bergantung pada sejumlah besar orang untuk melihat mereka agar mendapatkan banyak keuntungan. Dengan munculnya gerakan film indie, minat pada jenis film yang lebih beragam meningkat, yang lagi-lagi menciptakan lebih banyak kesempatan bagi siapa saja untuk terlibat dalam bisnis film (Moore, 2011).

Gerakan film indie tumbuh kuat; dengan meningkatnya permintaan untuk konten, semakin banyak pembuat film diberi kesempatan untuk bekerja dan mendistribusikan proyek-proyek mereka. Festival film tumbuh lebih dan lebih populer, bukan hanya 
sebagai tempat di mana penggemar film akan berkumpul untuk menyaksikan film, tetapi juga sebagai pasar untuk menaikkan pamor para sineas indie. Pemenang penghargaan film pendek (dan para pembuat filmnya) dapat memimpikan untuk tur lintas negara, dan kadang-kadang dunia, dengan sebuah film pendek, kadang-kadang dengan biaya yang dibayarkan oleh festival film yang mereka menangkan (Moore, 2011).

Film atau motion pictures ditemukan dari hasil pengembangan prinsip-prinsip fotografi dan proyektor. Film yang pertama kali diperkenalkan kepada publik Amerika Serikat adalah The Life of an American Fireman dan film The Great Train Robbery yang dibuat oleh Edwin S. Porter pada tahun 1903. Tetapi film The Great Train Robbery yang hanya berdurasi 11 menit dianggap sebagai film cerita pertama, karena telah menggambarkan situasi secara ekspresif, dan telah menjadi peletak dasar teknik editing yang baik (Ardianto et al., 2007).

Dalam manajemen produksi film, setidaknya ada lima tahapan produksi yang harus dilakukan oleh para sineas. Kelima tahap tersebut meliputi tahap development, praproduksi, produksi, post-produksi, dan distribusi. Manajemen produksi film adalah sebuah kegiatan yang bertujuan dan bertarget memberikan penambahan nilai terhadap produk melalui media audio-visual (film). Manajemen produksi film, di samping mengurusi hal fisik, juga berhubungan dengan usaha penciptaan/kreativitas, artistik, teknologi dan manusia. Proses manajemen akan berhubungan dengan semua unsur tersebut di atas (Setiawan, 2016).

Post-produksi atau pasca-produksi adalah tahap di mana produksi syuting film telah selesai dilakukan hingga film selesai namun belum dirilis. Tahap ini meliputi sinkronisasi gambar dan suara, rough cut, file management (EDL), online edit, final audio mix, film out $\&$ release married prints (Isfansyah, 2016). Di dalam tahap post-produksi film tersebut, terdapat proses penyuntingan gambar dan suara atau editing audio-visual. Stanley Kubrick mengatakan bahwa proses penyuntingan adalah tahapan dari sebuah produksi yang unik di dalam motion pictures. Semua aspek di dalam pembuatan film tedapat keunikan tersendiri karena memiliki beberapa unsur seperti fotografi, arah seni, penulisan, dan keserasian bunyi yang direkam menjadi kesatuan yang saling mendukung (Fachruddin, 2014).

Secara sederhana, proses editing merupakan usaha menyusun agar potonganpotongan gambar menjadi bercerita. Dalam kegiatan ini seorang editor akan merekonstruksi potongan-potongan gambar yang sudah diambil. Ada yang berpendapat bahwa editor adalah sutradara kedua. Tugas-tugas editor antara lain: (1) menganalisis skenario bersama sutradara; (2) melakukan pemilihan shot yang terpakai (OK) dan yang tidak terpakai (NG) sesuai shooting report; (3) menggabungkan antara gambar dan suara; (4) menyusun gambar menjadi bercerita; (5) berkonsultasi dengan sutradara atas hasil editingnya; dan (6) bertanggungjawab sepenuhnya atas keselamatan semua materi gambar dan suara (Isfansyah, 2016).

Dalam editing, terdapat dua teknik yang dapat digunakan oleh seorang editor, yakni teknik editing linear dan teknik editing non-linear. Teknik editing linear digunakan dengan cara merekam atau meng-copy gambar yang berada pada satu kaset ke kaset lainnya (tape-to-tape), jadi mirip seperti kita merekam lagu dengan menggunakan tape recorder. Keuntungan dari teknik editing ini adalah prosesnya tidak memakan waktu lama, sedangkan kelemahannya adalah gambar yang sudah direkam tidak dapat disusun ulang atau dipindah-pindahkan tanpa merekam kembali semua gambar dari awal (Fachruddin, 2014). Singkatnya, proses editing dilakukan dengan cara memotong bahan 
video yang diberi istilah klip dan disusun dengan menggunakan video player dan perekam VCR (Video Cassete Recorder), bisa juga menggunakan dua player jika ingin memasukan effect (Kustaman, 2018).

Teknik editing selanjutnya adalah teknik editing non-linear. Teknik editing ini dilakukan dengan cara menggunakan software komputer seperti Avid, Adobe Premiere Pro, Ulead, Pinacle, atau Final Cut Pro. Seluruh software editing ini memiliki keunggulan dan kelemahan masing-masing, yang biasanya menjadi bahan pertimbangan untuk tingkatan penggunaan. Biasanya untuk para pemula, software yang digunakan adalah Ulead dan Pinacle, karena mudah dioperasikan dan tidak terlalu membutuhkan spesifikasi komputer yang tinggi. Sedangkan para profesional lebih suka menggunakan Adobe Premiere Pro yang lebih menekankan pada kreativitas penggunanaya. Adapun Avid dan Final Cut Pro biasa digunakan untuk standar film dan juga program televisi atau broadcast pada umumnya. Final Cut Pro adalah sebuah software yang menggabungkan beberapa software untuk menyunting gambar dan juga membuat efek-efek visual maupun animasi, seperti Avid, Adobe Premiere Pro, Adobe After Effect, 3Dmax, dan Maya (Fachruddin, 2014). Dengan kata lain, teknik non-linear ini hampir sama dengan teknik linear, akan tetapi jauh lebih mudah karena prosesnya sudah menggunakan perangkat drag and drop, intensitas dan durasi effect bisa disesuaikan dengan kebutuhan (Kustaman, 2018).

Salah satu artikel pengabdian pada masyarakat (PPM) yang di dalamnya mendeskripsikan kegiatan PPM berupa pelatihan keterampilan menggunakan software komputer ditulis oleh Novan Wijaya. Wijaya memberikan pelatihan penggunaan software Adobe Illustrator dan Adobe Flash untuk mendesain logo vector di SMK Bina Cipta Palembang. Pelatihan ini bertujuan untuk: (1) memberikan pengalaman membuat logo vector secara praktis dan interaktif; (2) merangsang imajinasi dan kreativitas peserta untuk menerapkan warna pada logo vector sehingga menjadi lebih menarik; dan (3) mengimplementasikan teknologi secara langsung. Hasil dari pelatihan ini adalah para peserta dapat mengimplementasikan materi-materi yang diberikan dalam pelatihan menjadi sebuah logo dengan tingkat kreativitas masing-masing menggunakan software Adobe Illustrator dan Adobe Flash (Wijaya, 2016).

Berdasarkan paparan di atas, penulis melihat sebuah realita dalam konteks produksi film. Tahap post-produksi merupakan salah satu elemen terpenting dalam menentukan apakah sebuah film dapat dikatakan bagus atau tidak. Proses post-produksi memegang peranan penting dalam hal senuhan akhir sebuah film, di mana perpaduan visual dan audio yang tepat dari segi artistik maupun cerita amat menentukan kualitas sebuah film. Selain itu, seperti yang telah disampaikan di awal, di zaman teknologi yang praktis seperti sekarang ini, siapapun dapat membuat film menggunakan peralatan yang tidak terlalu kompleks. Bahkan, gawai yang memiliki fitur merekam dengan definisi tinggi juga sudah banyak beredar di pasaran dan bisa dijadikan alat untuk membuat sebuah film indie.

Pengambilan gambar yang baik dan benar dalam tahap produksi film-terlepas dari alat yang digunakan, apakah memakai kamera yang sederhana atau memakai kamera sinema profesional - tentu harus ditunjang dengan proses editing audio-visual yang baik dan benar. Teknik editing non-linear yang bersifat digital dapat digunakan secara efektif dengan menggunakan software editing dan spesifikasi komputer yang tepat. Berdasarkan alasan-alasan tersebut, pelatihan post-produksi (editing audio-visual) film indie ini dilakukan di Armidale English College (AEC), salah satu institusi yang berada di kawasan Soreang, Kabupaten Bandung. Para siswa AEC seringkali memproduksi film indie/film pendek, dan mayoritas termasuk ke dalam generasi millenials yang sudah akrab dengan 
peralatan audio-visual dan dunia digital, sehingga dipilih sebagai peserta pelatihan ini. Tujuan dari pelatihan ini adalah: (1) memberikan pemahaman kepada para peserta mengenai seluk-beluk editing audio-visual secara umum; dan (2) memberikan kemampuan praktis kepada para peserta dalam menggunakan software Adobe Premiere Pro untuk melakukan aktivitas editing audio-visual dalam tahap post-produksi dari film-film indie yang biasa mereka hasilkan.

\section{METODE PELAKSANAAN}

Kegiatan pelatihan post-produksi (editing audio-visual) film indie di Armidale English College, Kecamatan Soreang, Kabupaten Bandung yang telah dilakukan ini, dengan mempertimbangkan materi pelatihan dan para remaja berusia 17-19 tahun sebanyak 30 orang sebagai peserta pelatihan, masalah yang berkembang dan lingkungan yang mendukung, dalam pelaksanaannya menggunakan beberapa metode berikut, yaitu: (1) metode komunikasi bermedia (audio-visual); (2) metode ceramah/tutorial; (3) metode interaktif/dialog; (4) metode pre-test dan post-test; dan (5) metode simulasi. Penjelasannya adalah sebagai berikut:

1) Metode komunikasi bermedia dilakukan dengan menayangkan materi mengenai pengetahuan umum yang berkaitan dengan manajemen produksi film, program kerja dalam tahap post-produksi film, teknologi mutakhir dalam proses editing audiovisual, dan langkah-langkah editing audio-visual dengan software Adobe Premiere Pro menggunakan media audio visual. Metode ini lebih menarik karena disampaikan dengan video pendek, ilustrasi musik, dan kombinasi gambar yang menarik, sehingga materi-materi lebih mudah diterima oleh para peserta yang notabene merupakan generasi millenials yang telah terbiasa bersentuhan dengan konten-konten audio-visual melalui gawai yang mereka miliki.

2) ceramah dilakukan dengan memberikan wawasan umum kepada para peserta mengenai dasar-dasar teknik editing audio-visual disertai langkah-langkah pengerjaan editing audio-visual dengan menggunakan software Adobe Premiere Pro sampai para peserta pelatihan memahami dan mempraktikkan teknik-teknik editing audio-visual dengan baik dan benar.

3) Metode interaktif/dialog dilakukan dengan memberikan kesempatan kepada para peserta untuk menyampaikan pertanyaan seputar materi yang belum atau tidak dipahaminya, atau pertanyaan di luar materi tapi masih relevan dengan topik yang disampaikan. Para peserta juga dapat menceritakan pengalaman mereka yang berkenaan dengan produksi filmnya, mulai tahap pra-produksi sampai post-produksi.

4) Metode pre-test dan post-test dilakukan dengan memberi kuesioner tentang pengetahuan dan sikap para peserta terhadap program pelatihan editing audio-visual sebelum dan sesudah materi pelatihan disampaikan untuk mengetahui efektivitas kegiatan pelatihan yang dilakukan.

Metode simulasi kegiatan pelatihan dilakukan dengan cara membagi peserta menjadi 5 kelompok terlebih dahulu, di mana tiap kelompok berisi 6 orang peserta. Kemuadian, para peserta diinstruksikan untuk mengaplikasikan materi-materi editing audio-visual yang telah disampaikan dengan menggunakan gambar-gambar/video yang telah mereka ambil sebelumnya dengan mengolahnya dalam software Adobe Premiere Pro. Setelah film pendek tiap kelompok selesai, pemateri melakukan review hasil editing audio- 
visual para peserta untuk mengetahui kelebihan dan keurangan apa saja berdasarkan hasil tersebut.

\section{HASIL DAN PEMBAHASAN}

Pelatihan post-produksi (editing audio-visual) di Armidale English College, Kecamatan Soreang, Kabupaten Bandung bertujuan untuk mengembangkan keterampilan para peserta di bidang post-produksi, karena sentuhan akhir sebuah film ditentukan dengan seberapa baik teknik yang digunakan dalam kegiatan editing audiovisual sebuah film. Jika sentuhan akhir sebuah film dilakukan secara optimal, maka film yang dihasilkan juga akan lebih baik, dan hal itu berujung pada kepercayaan dan motivasi para peserta yang akan meningkat.

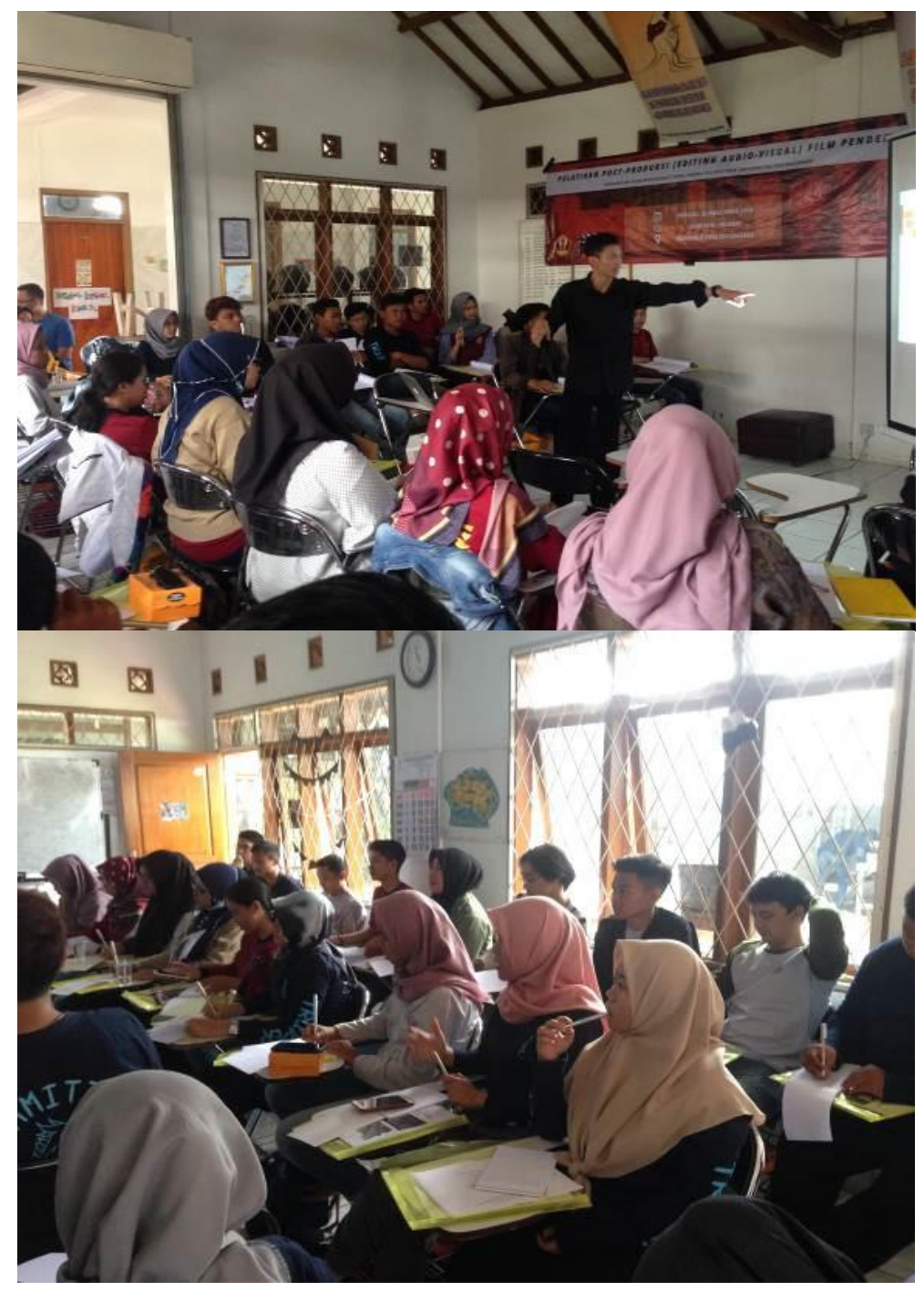

Gambar 1. Pemberian Materi Pelatihan Editing Audio-Visual oleh Rusli Kustaman, M.Sn.

Tahap pra-kegiatan yang tim lakukan dalam rangka program pelatihan ini adalah menghubungi pihak Armidale English College (AEC) untuk bekerjasama dalam penyediaan data peserta pelatihan dan keterlibatan dalam kegiatan pelatihan postproduksi (editing audio-visual) film indie. Selanjutnya, tim mendiskusikan materi pelatihan dengan praktisi editing audio-visual film, yaitu Rusli Kustaman, M.Sn., untuk 
menentukan materi editing audio-visual apa saja yang dapat diberikan pada para peserta pelatihan. Pada tahap ini, tim berdiskusi untuk mempersiapkan materi dan susunan acara saat pelatihan nanti. Pada tahap selanjutnya, kami mendiskusikan instrumen dan metode pelatihan yang akan digunakan saat kegiatan berlangsung. Pada tahap akhir persiapan, kami meyiapkan kuesioner untuk pre-test dan post-test serta kuesioner evaluasi pelatihan yang akan dibagikan kepada peserta pelatihan serta mendesain dan mencetak spanduk sebagai media luar ruang.

Para peserta pelatihan diberi materi-materi dan teknik-teknik editing audio-visual dengan menggunakan software Adobe Premiere Pro. Pelatihan ini dimulai dengan pengisian pre-test oleh para peserta yang berjumlah 30 orang. Setelah pengisian pre-test, sesi pelatihan langsung dimulai dengan materi-materi mengenai editing audio-visual oleh Rusli Kustaman, M.Sn., yaitu seorang dosen dan praktisi film yang memiliki kepakaran di bidang post-produksi film, baik itu editing visual maupun teknik-teknik audio dalam film. Selain memberikan materi, Rusli juga memberikan tutorial melakukan editing dengan menggunakan software Adobe Premiere Pro.

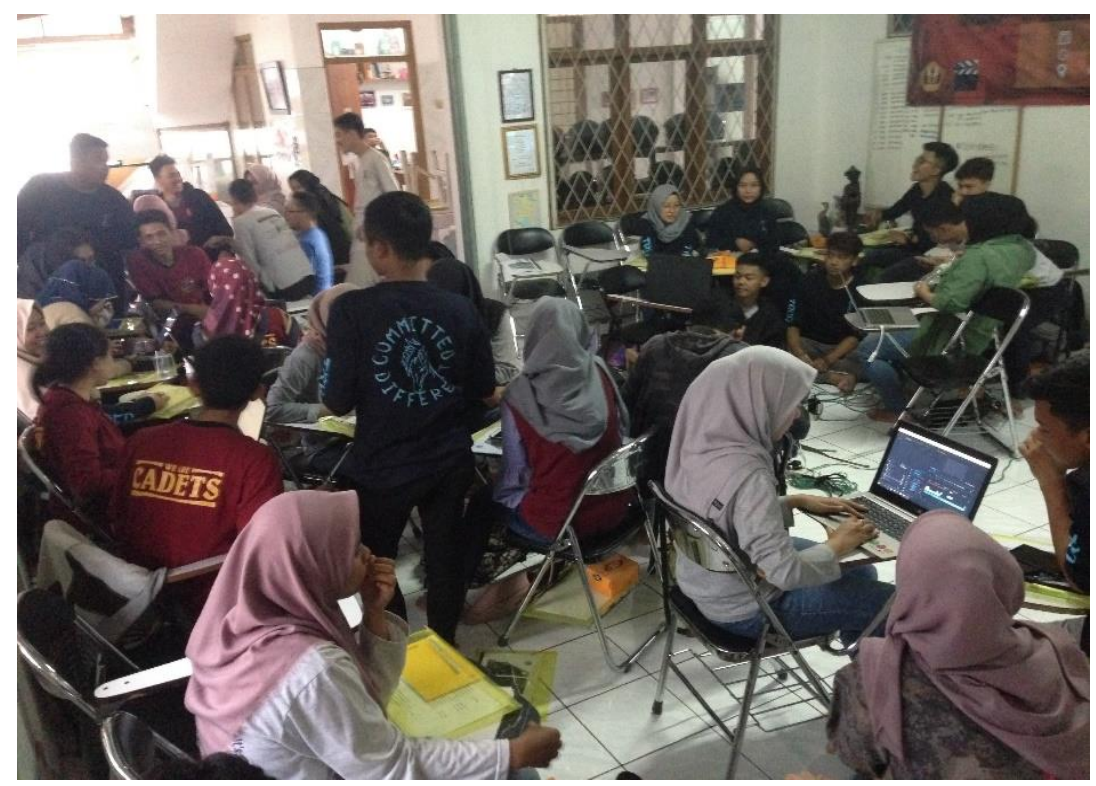

Gambar 2. Simulasi/Praktik Editing Audio-Visual Per Kelompok Peserta Menggunakan Software Adobe Premiere Pro

Kegiatan pelatihan ini diselingi istirahat, dan setelah istirahat, peserta diminta untuk mengisi post-test. Hal ini dilakukan untuk mengukur kognisi peserta mengenai materimateri editing audio-visual. Setelah pengisian post-test selesai, kegiatan pelatihan dilanjutkan dengan praktik editing audio-visual per kelompok dengan menggunakan software Adobe Premiere Pro. Kegiatan pelatihan ditutup dengan review hasil editing audiovisual per kelompok oleh pemateri. Deskripsi kegiatan pelatihan dijelaskan seperti berikut.

Saat sesi pelatihan dilangsungkan di AEC, sesi pelatihan dimulai dengan pembagian pre-test kepada para peserta. Setelah pengisian pre-test selesai, materi-materi mengenai editing audio-visual diberikan kepada para peserta. Materi-materi ini mencakup teknikteknik pengambilan gambar yang baik, pengetahuan dasar mengenai rasio dan jenis-jenis video, sampai pada tutorial melakukan aktivitas editing audio-visual dengan menggunakan software Adobe Premiere Pro. 
Setelah pemberian materi dan tutorial menggunakan software Adobe Premiere Pro selesai, para peserta dibagi menjadi 5 kelompok yang masing-masing terdiri dari 6 orang peserta. Kelompok-kelompok peserta ini kemudian diinstruksikan untuk mengaplikasikan teknik-teknik editing audio-visual menggunakan software Adobe Premiere Pro. Video-video pendek yang diolah dalam software tersebut adalah video-video pendek peserta yang telah diambil sebelumnya. Setiap kelompok diberi waktu 120 menit untuk menyelesaikan proses editing audio-visual. Setelah selesai, pemateri (Rusli Kustaman, M.Sn.) melakukan proses review hasil karya tiap kelompok peserta. Dalam proses review ini, Rusli memberikan kritik dan masukan terhadap hasil kerja tiap kelompok peserta. Sesi pelatihan ditutup dengan pemberian sertifikat, plakat, dan cinderamata dari penyelenggara PPM kepada narasumber serta tempat diselenggarakannya pelatihan, yaitu Armidale English College.

Sebelum kegiatan pelatihan benar-benar ditutup, tim PPM membagikan lembar posttest kepada para peserta dengan tujuan untuk mengetahui tingkat pengetahuan dan sikap para peserta terhadap materi-materi dan kegiatan pelatihan editing audio-visual. Ternyata setelah lembar pre-test dan post-test-nya selesai diolah, hasil test $95 \%$ peserta pelatihan secara kognitif mengalami peningkatan (menunjukkan adanya peningkatan pemahaman) mengenai tahap post-produksi film dalam tataran editing audio-visual. Tim PPM juga membagikan kuesioner evaluasi pelatihan; dari kuesioner evaluasi terlihat bahwa peserta cenderung menilai positif, baik dalam konteks materi pelatihan maupun cara penyampaian pemateri.

Setiap individu dalam tim pelaksana kegiatan PPM ini merupakan individuindividu unggulan dengan kredibilitas yang baik. Keahlian yang dimiliki tersebut tentu saja mampu memberikan kontribusi yang maksimal dalam pelaksanaan pelatihan ini. Adapun hasil yang dicapai dalam kegiatan PPM Pelatihan Post-Produksi (Editing AudioVisual) Film Indie di Armidale English College (AEC), Kecamatan Soreang, Kabupaten Bandung ini adalah:

1) Para sivitas akademika di AEC umumnya dan khusunya para peserta pelatihan secara kognitif memiliki pemahaman yang lebih baik mengenai editing audio-visual film indie. Mereka memiliki pengetahuan dan mendapatkan pemahaman mengenai penggunaan software Adobe Premiere Pro untuk editing audio-visual dalam tahap postproduksi film indie.

2) Para sivitas akademika di AEC umumnya dan khusunya para peserta pelatihan secara afektif memiliki keinginan dan motivasi untuk menggunakan software Adobe Premiere Pro untuk editing audio-visual dalam tahap post-produksi film indie yang mereka produksi.

Para sivitas akademika di AEC umumnya dan khususnya para peserta pelatihan secara psikomotorik memiliki kemapuan untuk mengoperasikan software Adobe Premiere Pro dalam tahap post-produksi film indie mereka melalui aktivitas editing audio-visual. Dengan kemampuan editing audio-visual yang baik, mereka akan lebih percaya diri dan termotivasi ketika akan mempromosikan film-film indie karya mereka, karena kualitas audio-visual film yang dapat bersaing dengan karya-karya film indie lainnya.

\section{SIMPULAN}

Hasil yang dicapai dalam kegiatan PPM Pelatihan Pelatihan Post-Produksi (Editing Audio-Visual) Film Indie di Armidale English College, Kecamatan Soreang, Kabupaten 
Bandung ini adalah para peserta pelatihan mengalami peningkatan pemahaman dan keterampilan dalam konteks post-produksi film indie, khususnya dalam proses editing audio-visual film menggunakan software Adobe Premiere Pro.

Dalam tataran kognitif, para peserta pelatihan memiliki pemahaman yang lebih baik mengenai editing audio-visual film indie. Mereka memiliki pengetahuan dan mendapatkan pemahaman mengenai penggunaan software Adobe Premiere Pro untuk editing audio-visual dalam tahap post-produksi film indie; dalam tataran afektif, para peserta pelatihan memiliki keinginan dan motivasi untuk menggunakan software Adobe Premiere Pro untuk editing audio-visual dalam tahap post-produksi film indie yang mereka produksi; sedangkan dalam tataran psikomotorik, para peserta pelatihan memiliki kemapuan untuk mengoperasikan software Adobe Premiere Pro dalam tahap post-produksi film indie mereka melalui aktivitas editing audio-visual.

Berdasarkan hasil yang diperoleh dalam program kegiatan PPM ini, saran yang dapat diberikan oleh penulis adalah pelatihan-pelatihan dalam konteks produksi film indie lebih baik jika dilakukan full-package; dalam artian, seluruh konsep dalam berbagai aspek film seharusnya disampaikan agar tercipta kesinambungan dan pemahaman yang lengkap dalam tataran kognitif, afektif, dan psikomotor peserta pelatihan. Pelatihan produksi film indie yang biasanya dilakukan oleh rumah produksi atau komunitaskomunitas film hendaknya diisi berbagai materi komprehensif mulai dari tahap development (pengayaan ide cerita film), pra-produksi, produksi, post-produksi, sampai pada tahap distribusi dan promosi film, sehingga para sineas Indonesia dapat menjadi insan perfilman yang lengkap dan dapat bersaing di dunia film nasional, regional, bahkan internasional.

\section{REFERENSI}

Ardianto, E., Komala, L., \& Karlinah, S. (2007). Komunikasi massa: Suatu pengantar. Bandung: Simbiosa Rekatama Media.

Fachruddin, A. (2014). Dasar-dasar produksi televisi: produksi berita, feature, laporan investigasi, dokumenter, dan teknik editing. Jakarta: Prenadamedia Group.

Isfansyah, I. (2016). Film production workflow. Sumedang: Unpad.

Kustaman, R. (2018). Audio Video Editing. Bandung.

Moore, J. (2011). Short film distribution: Film festivals, the internet, and self-promotion. Dulles: Mercury Learning.

Putri, I. P. (2013). Mendefinisikan ulang film indie: Deskripsi perkembangan sinema independen Indonesia. Jurnal Komunikasi Indonesia, 2(2), 119-128.

Setiawan, I. (2016). Manajemen produksi TV dan film. Bandung: Sekolah Tinggi Teknologi Bandung.

Siregar, H. A. A. (2011). Kontribusi teori interpretasi psikoanalisis dan hermeneutik terhadap proses analisis/pengkajian film. Jurnal Sosioteknologi, 23(10), 1077-1092. 
Wijaya, N. (2016). Pelatihan membuat desain logo vector menggunakan adobe illustrator dan adobe flash di SMK Bina Cipta Palembang. Jurnal Pengabdian Pada Masyarakat, $1(1), 25-29$. 